\title{
Clinical patterns and associated comorbidities of vitiligo in Kandahar, Afghanistan. A case-control study
}

\section{Bilal Ahmad Rahimi', Khushhal Farooqi ${ }^{2}$, Najibullah Fazli ${ }^{3}$}

${ }^{1}$ Department of Pediatrics, Faculty of Medicine, Kandahar University, Kandahar, Afghanistan, ${ }^{2}$ Department of Dermatology, Faculty of Medicine, Kandahar University, Kandahar, Afghanistan, ${ }^{3}$ Department of Internal Medicine, Faculty of Medicine, Kandahar University, Kandahar, Afghanistan

Corresponding author: Dr. Bilal Ahmad Rahimi, E-mail: drbilal77@yahoo.com

\begin{abstract}
Background: Vitiligo is an idiopathic acquired depigmentary skin/mucous membrane disorder. Main objective of this study was to find out demographic data, clinical patterns, and comorbidities associated with vitiligo in Kandahar, Afghanistan. Material and Methods: This was a case-control study conducted in Kandahar University Teaching Hospital between July 2017-June 2018. Descriptive statistics, Chi-square test, and logistic regression were used for data analysis. Results: A total of 400 patients (200 cases and 200 controls) were recruited. Mean age \pm standard deviation (SD) of cases were $21.7 \pm 13.8$ with most of the patients $(77 / 200[38.5 \%])$ in age group 11-20 years. Female cases were more $(107 / 200[53.5 \%])$ than males. Family history of vitiligo, accompanying altered immunity and autoimmunity disorders, psychological stress, premature graying of hair, halo nevus, vitamin $\mathrm{D}$ deficiency, vitamin $\mathrm{B}_{12}$ deficiency, and folate deficiency were present in 60/200 (30\%), 26/195 (13.3\%), 95/200 (47.5\%), 31/200 (15.5\%), 24/200 (12\%), 22/200 (11\%), $16 / 200(8 \%)$, and 14/200 (7\%) of the cases, respectively. Most of the patients (148/200 [74\%]) had vulgaris, followed by focal (30/200 [15\%]) and segmental (11/200 [5.5\%]) types of vitiligo. Logistic regression analysis showed that family history, accompanying altered immunity and autoimmunity disorders, premature graying of hair, halo nevus, and atopic diathesis were the possible risk factors of vitiligo with odds ratios of 37.1, 9.0, 6.0, 13.9, and 3.9 respectively. Conclusions: Vitiligo affects women more than men, observed mostly in second decade of life. Vitiligo vulgaris is the most prevalent type.
\end{abstract}

Key words: Vitiligo; Kandahar; Afghanistan; Clinical patterns; Comorbidities; Skin

\section{INTRODUCTION}

Vitiligo is an acquired, idiopathic depigmentation disorder of skin and hair with characteristic white macules and patches. Vitiligo affects $0.1-2 \%$ of global population [1]. Highest incidence of this disorder is observed in India and Mexico [2]. In India, its prevalence is nearly $3-4 \%$ of patients visiting skin clinics of different hospitals [3]. Its prevalence is nearly equal between males and females [4]. Vitiligo causes decreased self-esteem, poor body images, problems in sexual relations, as well as cosmetically and psychologically devastating. Most of its impact on quality of life is observed in individuals with darker skin phototype [5].

Vitiligo is a refractory skin disorder for which the risk factors and treatment modalities have not yet been established [6]. Vitiligo has three clinical types, i.e., generalized vitiligo (spreads widely over the body), segmental vitiligo (dermatomal spread along the course of a nerve), and localized vitiligo (it is unclassifiable and can develop into either generalized or segmental type in the future) [7]. Pathogenesis of vitiligo has not yet been explained fully. Some of the proposed theories are autoimmune [8],

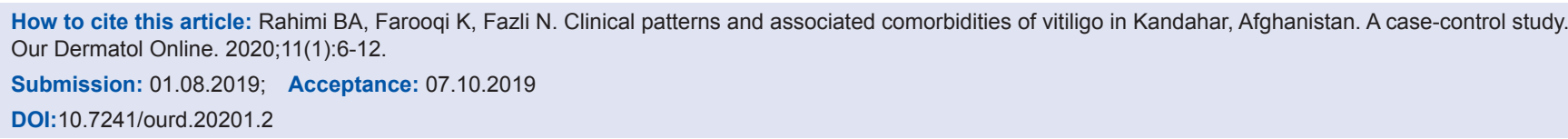


neurogenic [9], self-destruct [10], genetic factors [11], biochemical defects [12], and recently transepidermal malanocytorrhagy [13]. Its onset is gradual and asymptomatic. The initial lesion usually has depigmented macules different in size, shape, number, and location with unpredictable course. However, it is progressive in $>80 \%$ of patients [14]. Patients with a positive family history, mucosal involvement, isomorphic Koebner's phenomenon, and nonsegmental vitiligo are usually associated with progressive vitiligo. Presence of positive family history can be observed in 20-30\% of cases [2] with polygenic or autosomal dominant gene inheritance. Vitiligo seems to be related with autoimmune disorders like thyroid disorders (especially hypothyroidism) [15], alopecia areata, type 1 diabetes mellitus [16,17], SLE (systemic lupus erythematosus), psoriasis, rheumatoid arthritis, Addison's diseases, and pernicious anemia $[18,19]$. The most commonly occurring autoimmune disorder is hypothyroidism.

Afghans are suffering from vitiligo too. This disorder is creating problems for all age groups, especially causing cosmetic problems and stigma in female and male adolescents before their marriages. Currently there is no published data showing the situation of vitiligo in Afghanistan. Null-hypothesis of our study was there is no difference in demographic data and associated factors between cases and controls. Main objectives of this study were to find out the epidemiology of vitiligo by observing the demographic data, clinical patterns of vitiligo, as well as common possible risk factors associated with vitiligo in Kandahar, Afghanistan.

\section{MATERIALS AND METHODS}

\section{Study Design and Period}

This was a case-control study. Data was collected from the patients who fulfilled the eligible criteria of the study during l-year-period (July 2017-June 2018).

\section{Study Population}

The study population was comprised of cases (patients having clinically diagnosed vitiligo) and controls (patients not having vitiligo) attending skin OPD clinic of Kandahar University Teaching Hospital, Kandahar, Afghanistan. Controls were sex- and age-matched randomly selected patients.

\section{Research Question}

What are the demographic data, clinical patterns, and possible risk factors of vitiligo in Kandahar, Afghanistan?

\section{Primary Objective}

To find out the epidemiology of vitiligo by observing the demographic data and clinical patterns of vitiligo.

\section{Secondary Objective}

To assess the common possible risk factors associated with vitiligo in Kandahar, Afghanistan.

\section{Inclusion Criteria}

- Patients having clinically diagnosed vitiligo

- All age and sex groups

- Patient consenting to the study

- Permanent residents of Kandahar.

\section{Exclusion Criteria}

- Patients who do not want to take part in the study

- Patients with depigmentation of skin due to causes other than vitiligo

- Control group patient with autoimmune or altered immune disorders.

- Control group patient with family member in case group.

\section{Sample Size Calculations}

Sample size was determined using the formula: $\mathrm{n}=$ $\mathrm{Z} 2 \mathrm{pq} / \mathrm{d}^{2}$. Our sample size was 200 patients. As it was a case-control study, 200 more subjects were added as controls.

\section{Ethical Considerations}

Written informed consents were taken from all the patients prior to the study. Names and other identification information of all the patients will not be disclosed. Ethical approval was taken from Kandahar University Ethics Committee.

\section{Data Analysis}

Data was analyzed using SPSS statistical software (version 22). For the analysis of data; descriptive statistics, Chi-square test, and logistic regression were 
used. $P$-value of $<0.05$ was assumed as statistically significant.

\section{Operational Definitions}

1. Clinical patterns of vitiligo [20]

- Focal vitiligo: lesions confined to one or a few patches localized in a particular area.

- Segmental vitiligo: lesions distributed in a segmental/dermatomal pattern.

- Acrofacial vitiligo: lesions noted over both face and acral regions.

- Vitiligo vulgaris: lesions affecting many parts of the body.

- Mucosal vitiligo: lesions confined only to mucous membranes.

- Universal vitiligo: when more than $80 \%$ of the skin is depigmented.

2. Signs and symptoms of vitamin D deficiency [21]

- Getting sick or infected often, fatigue and tiredness, bone and back pain, depression, impaired wound healing, bone loss, hair loss, muscle pain.

3. Signs and symptoms of B12 deficiency [22]

- Pale or jaundiced skin, weakness and fatigue, sensation of pins and needles, changes to mobility, glossitis and mouth ulcers, breathlessness and dizziness, blurred vision, mood changes, high temperature.

4. Signs and symptoms of folate deficiency [23]

- Persistent fatigue, Weakness, Lethargy, Pale skin, Shortness of breath, Irritability.

\section{RESULTS}

A total of 400 patients were recruited for this study, with 200 patients as cases and 200 as controls. The age and gender distribution were same in cases and controls with no statistically significant difference. Mean age \pm standard deviation (SD) of the patients were $21.7 \pm 13.8$ years and $21.1 \pm 12.7$ years in cases and controls, respectively. Demographic characteristics of patients enrolled in this study are summarized in Table 1 . More than half $(107 / 200$ [53.5\%] and 108/200 [54\%]) of the patients were females in both cases and controls, respectively. Family history of vitiligo was present in 60/200 (30\%) and $3 / 200(1.5 \%)$ patients in cases and controls, respectively ( $p$-value <0.001). Among these patients, $37 / 66$ (56.1\%) were unemployed while 29/66 (43.9\%) employed. More than half of the patients $(35 / 66$ [53\%]) were students. Most of the patients (77/200 [38.5\%] and 71/200 [35.5\%])

\begin{tabular}{lcclcc}
$\begin{array}{l}\text { Table 1: Age distribution of the patients } \\
\text { Age }\end{array}$ & \multicolumn{2}{c}{ Cases } & & \multicolumn{2}{c}{ Controls } \\
\cline { 2 - 3 } \cline { 5 - 6 } $\begin{array}{l}\text { group } \\
\text { (years) }\end{array}$ & Frequency & Percent (\%) & & Frequency & Percent (\%) \\
\hline $1-10$ & 40 & 20 & & 45 & 22.5 \\
$11-20$ & 77 & 38.5 & & 71 & 35.5 \\
$21-30$ & 37 & 18.5 & & 39 & 19.5 \\
$31-40$ & 29 & 14.5 & & 30 & 15 \\
$41-50$ & 8 & 4 & & 7 & 3.5 \\
$51-60$ & 5 & 2.5 & & 5 & 2.5 \\
$61-70$ & 4 & 2 & & 3 & 1.5 \\
$>70$ & 0 & 0 & & 0 & 0 \\
Total & 200 & 100 & & 200 & 100 \\
\hline
\end{tabular}

were of age group 11-20 years in both cases and controls, respectively.

Among cases, most of the patients (148/200 [74\%]) had vulgaris, followed by focal $(30 / 200$ [15\%]) and segmental (11/200 [5.5\%]) types of vitiligo. Different patterns of lesions are shown in Table 2.

Accompanying disorders with altered immunity and autoimmunity were present in 26/195 (13.3\%) cases and $2 / 200$ (1\%) controls as compared to $169 / 195(86.7 \%)$ cases and 198/200 (99\%) controls not having any accompanying immune diseases. Among 26 cases having accompanying altered immunity and autoimmunity disorders, 6/26 (23.1\%) were having alopecia areata while 6/26 (23.1\%) were having atopic dermatitis. Only 2 control group patients were having accompanying altered immunity and autoimmunity disorders, with one patient having atopic dermatitis while one patient having psoriasis (Table 3).

Accompanying disorders with no altered or autoimmunity present among cases and controls are summarized in Table 4. Isomorphic phenomenon, premature graying of hair, and halo nevus were present in $63(31.5 \%), 31(15.5 \%)$, and $24(12 \%)$ cases while in $0(0 \%), 5(2.5 \%)$, and $2(1 \%)$ controls; respectively. Vitamin $\mathrm{D}$, vitamin $\mathrm{B}_{12}$, and folate deficiencies were present in $22(11 \%), 16(8 \%)$, and $14(7 \%)$ cases while in $59(29.5 \%), 3(1.5 \%)$, and $2(1 \%)$ controls; respectively. In all the above diseases, $p$-value was $<0.05$.

Logistic regression was conducted for all the variables with $p$-value $<0.05$. Highest odds ratio was seen in family history (37.12 with 95\% CI 9.87-139.63) followed by halo nevus (13.89 with 95\%CI 2.5-77.06) and accompanying altered immunity and autoimmunity disorders (9.04 with 95\% CI 1.55-52.82). Lowest odds ratio was seen in vitamin $\mathrm{D}$ deficiency $(0.09$ with 95\%CI 0.03-0.29) followed by folate deficiency (1.32 
Table 2: Demographic characteristics of patients in both cases and controls

\begin{tabular}{|c|c|c|c|c|c|}
\hline \multirow[t]{2}{*}{ Variable } & \multicolumn{2}{|c|}{ Cases } & \multicolumn{2}{|c|}{ Controls } & \multirow[t]{2}{*}{$p$-value } \\
\hline & Frequency & Percent (\%) & Frequency & Percent (\%) & \\
\hline Gender & & & & & 0.92 \\
\hline Male & 93 & 46.5 & 92 & 46 & \\
\hline Female & 107 & 53.5 & 108 & 54 & \\
\hline Total & 200 & 100 & 200 & 100 & \\
\hline Occupation & & & & & 0.16 \\
\hline Self-employed & 24 & 36.4 & 25 & 39.1 & \\
\hline Government employee & 5 & 7.6 & 3 & 4.7 & \\
\hline House wife & 2 & 3 & 0 & 0 & \\
\hline Student & 35 & 53 & 36 & 56.3 & \\
\hline Total & 66 & 100 & 64 & 100 & \\
\hline Place of living & & & & & 1.0 \\
\hline Urban & 126 & 63 & 126 & 63 & \\
\hline Rural & 74 & 37 & 74 & 37 & \\
\hline Total & 200 & 100 & 200 & 100 & \\
\hline \multicolumn{6}{|l|}{ Place of living } \\
\hline Kandahar City & 121 & 60.5 & 126 & 63 & \\
\hline Arghandab District & 5 & 2.5 & 3 & 1.5 & \\
\hline Spin Boldak District & 13 & 6.5 & 13 & 6.5 & \\
\hline Shah Wali Kot District & 6 & 3 & 12 & 6.0 & \\
\hline Arghistan District & 3 & 1.5 & 1 & 0.5 & \\
\hline Maiwand District & 7 & 3.5 & 3 & 1.5 & \\
\hline Zharai District & 8 & 4 & 3 & 1.5 & \\
\hline Panjwai District & 8 & 4 & 10 & 5 & \\
\hline Takhta Pul District & 2 & 1 & 7 & 3.5 & \\
\hline Daman District & 8 & 4 & 9 & 4.5 & \\
\hline Dand District & 15 & 7.5 & 9 & 4.5 & \\
\hline Ghorak District & 1 & 0.5 & 2 & 1 & \\
\hline Khak Rez District & 2 & 1 & 1 & 0.5 & \\
\hline Nesh District & 1 & 0.5 & 1 & 0.5 & \\
\hline Total & 200 & 100 & 200 & 100 & \\
\hline
\end{tabular}

Table 3: Different patterns of lesions

\begin{tabular}{lcc}
\hline Pattern of lesion & \multicolumn{2}{c}{ Cases } \\
\cline { 2 - 3 } & Frequency & Percent (\%) \\
\hline Vulgaris & 148 & 74 \\
Focal & 30 & 15 \\
Segmental & 11 & 5.5 \\
Acrofacial & 7 & 3.5 \\
Mucosal & 4 & 2 \\
Universal & 0 & 0 \\
Total & 200 & 100 \\
\hline
\end{tabular}

with 95\% CI 0.05-31.93) and psychological stress (1.57 with 95\% CI 0.84-2.94) (Table 5). Logistic regression of our data showed that family history, accompanying altered immune or autoimmune disorders, premature graying of hair, halo nevus, and atopic diathesis were the possible risk factors of vitiligo with odds ratios of 37.1, 9.0, 6.0, 13.9, and 3.9 respectively (Table 6).

Blood groups of all the patients (both cases and controls) were checked. In cases; 56 (28\%), 54 (27\%), $53(26.5 \%), 36(18 \%)$, and 1 (0.5\%) patients were having $\mathrm{A}(\mathrm{Rh}+), \mathrm{B}(\mathrm{Rh}+), \mathrm{O}(\mathrm{Rh}+), \mathrm{AB}(\mathrm{Rh}+)$, and $\mathrm{O}(\mathrm{Rh}-)$ blood groups, respectively. Meanwhile in controls;
$46(23 \%), 63(31.5 \%), 48(24 \%)$, and $43(21.5 \%)$ patients were having $\mathrm{A}(\mathrm{Rh}+), \mathrm{B}(\mathrm{Rh}+), \mathrm{O}(\mathrm{Rh}+)$, and $\mathrm{AB}(\mathrm{Rh}+)$ blood groups, respectively (Table 7$)$.

\section{DISCUSSION}

In this case-control study 400 patients were recruited with 200 cases and 200 controls. In our study, more than half of the patients were females (107/200 [53.5\%]). Similar results have been reported from studies in Turkey (62.5\%) [24] and Saudi Arabia (53.5\% [19] $56 \%$ [25]). Increased number of females among vitiligo patients is may be due to the fact that females are usually more concerned about pigmentation changes of their skin. So social stigma and marital concerns prompt females to seek early medical consultation.

Vitiligo can occur in all age groups with highest prevalence among young adults [26]. In our study, mean age of the patients was 21.7 years, with majority (38.5\%) of patients in 11-20 years' age group. A study in Tunisia showed that most $(66 \%)$ of the patients 
developed vitiligo in their adulthood [27], mean age of occurrence of vitiligo was 18.8 years among Chinese patients [28], while a Turkish study reported that vitiligo occurred early in life with mean age of 10 years [(24)]. Some studies have reported mean age ranging from 24.5-34 years [29-34].

Table 4: Accompanying disorders with altered immunity and autoimmunity

\begin{tabular}{|c|c|c|c|c|}
\hline \multirow[t]{2}{*}{ Disorder } & \multicolumn{2}{|c|}{ Cases } & \multicolumn{2}{|c|}{ Controls } \\
\hline & Frequency & Percent (\%) & Frequency & Percent (\%) \\
\hline $\begin{array}{l}\text { Alopecia } \\
\text { areata }^{\dagger}\end{array}$ & 6 & 23.1 & 0 & 0 \\
\hline $\begin{array}{l}\text { Atopic } \\
\text { dermatitis*}^{*}\end{array}$ & 6 & 23.1 & 1 & 50 \\
\hline 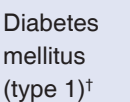 & 3 & 11.5 & 0 & 0 \\
\hline $\begin{array}{l}\text { Lichen } \\
\text { planus }^{*}\end{array}$ & 5 & 19.2 & 0 & 0 \\
\hline Psoriasis* & 4 & 15.4 & 1 & 50 \\
\hline Total & 26 & 100 & 2 & 100 \\
\hline
\end{tabular}

* Disorder with altered immunity. ${ }^{+}$Disorder with autoimmunity.
In our study family history was present in $30 \%$ of cases as compared to $1.5 \%$ controls ( $p$-value $<0.001)$. Similarly, family history of vitiligo (42.8\% [19], 25\% [31], 24\% [32], and 18\% [29]) has also been observed in other studies.

Most of the patient $(63 \%)$ in our study were living in urban areas, where there are many environmental pollutants. A study in India also reported that majority of the patients (78\%) were living in urban areas [35]. Contrary, a study in China showed that there is no significant difference between rural and urban residents [36]. In the etiology of vitiligo, Slominki et al. pointed out several environmental factors; including sunlight, stress, and extreme exposure to pesticides [37].

Most of the patients $(74 \%)$ in our study had vulgaris type of vitiligo. Similarly, other studies showed higher numbers with 64.9\% [35], 49.6 [38], 57.4\% [39],

Table 5: Accompanying disorders with no altered or auto-immunity

\begin{tabular}{|c|c|c|c|c|c|}
\hline \multirow[t]{2}{*}{ Disorder } & \multicolumn{2}{|c|}{ Cases } & \multicolumn{2}{|c|}{ Controls } & \multirow[t]{2}{*}{$p$-value } \\
\hline & Frequency & Percent (\%) & Frequency & Percent (\%) & \\
\hline Psychological Stress & & & & & $<0.001$ \\
\hline Present & 95 & 47.5 & 46 & 23 & \\
\hline Absent & 105 & 52.5 & 154 & 77 & \\
\hline Total & 200 & 100 & 200 & 100 & \\
\hline Isomorphic phenomenon & & & & & $<0.001$ \\
\hline Present & 63 & 31.5 & 0 & 0 & \\
\hline Absent & 137 & 68.5 & 200 & 100 & \\
\hline Total & 200 & 100 & 200 & 100 & \\
\hline Premature graying of hair & & & & & $<0.001$ \\
\hline Present & 31 & 15.5 & 5 & 2.5 & \\
\hline Absent & 169 & 84.5 & 195 & 97.5 & \\
\hline Total & 200 & 100 & 200 & 100.0 & \\
\hline Halo nevus & & & & & $<0.001$ \\
\hline Present & 24 & 12 & 2 & 1 & \\
\hline Absent & 176 & 88 & 198 & 99 & \\
\hline Total & 200 & 100 & 200 & 100 & \\
\hline Atopic diathesis & & & & & 0.001 \\
\hline Present & 19 & 9.5 & 3 & 1.5 & \\
\hline Absent & 180 & 90.5 & 197 & 98.5 & \\
\hline Total & 199 & 100 & 200 & 100 & \\
\hline Vitamin D deficiency & & & & & $<0.001$ \\
\hline Present & 22 & 11 & 59 & 29.5 & \\
\hline Absent & 178 & 89 & 141 & 70.5 & \\
\hline Total & 200 & 100 & 200 & 100 & \\
\hline Vitamin $\mathrm{B}_{12}$ deficiency & & & & & 0.002 \\
\hline Present & 16 & 8 & 3 & 1.5 & \\
\hline Absent & 184 & 92 & 197 & 98.5 & \\
\hline Total & 200 & 100 & 200 & 100 & \\
\hline Folate deficiency & & & & & 0.002 \\
\hline Present & 14 & 7 & 2 & 1 & \\
\hline Absent & 186 & 93 & 198 & 99 & \\
\hline Total & 200 & 100 & 200 & 100 & \\
\hline
\end{tabular}


Table 6: Logistic regression for possible risk factors of vitiligo

\begin{tabular}{lccc}
\hline Variable & OR (Odds Ratio) & 95\% Cl & $p$-value \\
\hline Family history & 37.12 & $9.87-139.63$ & $<0.001$ \\
Accompanying & 9.04 & $1.55-52.82$ & 0.014 \\
altered immunity and & & & \\
autoimmunity disorders & & & \\
Premature graying of hair & 6.01 & $1.74-20.68$ & 0.004 \\
Halo nevus & 13.89 & $2.5-77.06$ & 0.003 \\
Atopic diathesis & 3.86 & $0.86-17.42$ & 0.079 \\
Psychological stress & 1.57 & $0.84-2.94$ & 0.16 \\
Vitamin D deficiency & 0.09 & $0.03-0.29$ & $<0.001$ \\
Vitamin $B_{12}$ deficiency & 3.28 & $0.16-65.8$ & 0.44 \\
Folate deficiency & 1.32 & $0.05-31.93$ & 0.86 \\
\hline
\end{tabular}

Table 7: Blood groups of cases and controls

\begin{tabular}{lccccc}
\hline & \multicolumn{2}{c}{ Cases } & & \multicolumn{2}{c}{ Controls } \\
\cline { 2 - 3 } \cline { 5 - 6 } & Frequency & Percent (\%) & & Frequency & Percent (\%) \\
\hline $\mathrm{A}(\mathrm{Rh}+)$ & 56 & 28 & & 46 & 23 \\
$\mathrm{~B}(\mathrm{Rh}+)$ & 54 & 27 & & 63 & 31.5 \\
$\mathrm{O}(\mathrm{Rh}+)$ & 53 & 26.5 & & 48 & 24 \\
$\mathrm{AB}(\mathrm{Rh}+)$ & 36 & 18 & & 43 & 21.5 \\
$\mathrm{O}(\mathrm{Rh}-)$ & 1 & 0.5 & & 0 & 0 \\
Total & 200 & 100 & & 200 & 100 \\
\hline
\end{tabular}

$59.8 \%$ [26], and $42.3 \%$ [40] of patients having vulgaris pattern. Contrary, other studies reported localized type in most of the cases $(77 \%$ [41], 60\% [31], 48.5\% [42], and $32.4 \%$ [33]).

There is association of vitiligo with autoimmune disorders [25]. In our study $13.3 \%$ of the cases while $1 \%$ of the controls were having accompanying altered immunity and autoimmunity disorders which was statistically significant ( $p$-value $<0.001)$. Our main observed accompanying altered immunity and autoimmunity disorders were alopecia areata and atopic dermatitis. Other studies have also reported association of autoimmune disorders in Canada (19\%) [43], North America and UK (23\%) [44], and China (8\%) [44].

For finding the possible risk factors of vitiligo, we conducted logistic regression of our data. It showed that family history, accompanying altered immune or autoimmune disorders, premature graying of hair, halo nevus, and atopic diathesis were the risk factors of vitiligo with odds ratios of 37.1, 9.0, 6.0, 13.9, and 3.9 respectively. In a large retrospective Japanese study with 713 vitiligo patients, younger age of onset and higher antinuclear antibodies (ANA) were the main risk factors [6]. A retrospective Chinese study on 101 vitiligo-associate halo nevus patients showed that personal history of thyroid diseases, Koebner phenomenon, multiple halo nevus, and familial history of vitiligo were risk factors associated with halo nevus vitiligo [45].
There were limitations in our study. Data was collected among patients attending one hospital. It would be better if data was collected randomly from different hospitals and clinics of the city and surrounding districts. Deficiencies of vitamin D, vitamin B12, and folate were detected using clinical signs and symptoms, not by laboratory examinations. Also, we could not work on all the possible risk factors of vitiligo (especially thyroid disorders). All these were due to limited funds, facilities, and personnel. Further more detailed studies are needed (in Kandahar and other regions of Afghanistan) to describe the demographic features, clinical patterns, and possible risk factors of vitiligo in details.

In conclusion, vitiligo affects women slightly more than men. Mean age of vitiligo patients is 21.7 years, observed mostly in second decade of life. Vitiligo vulgaris is the most prevalent type, affecting $74 \%$ of the patients. Common risk factors of vitiligo are family history, accompanying altered immunity/autoimmunity disorders, premature graying of hair, halo nevus, and atopic diathesis.

\section{ACKNOWLEDGEMENTS}

We present our highest and sincere thanks to the authorities and lecturers of Kandahar University (especially Faculty of Medicine), Kandahar, Afghanistan for their kind support. We are also thankful of our study patients for helping us do this research.

\section{Statement of Human and Animal Rights}

All procedures followed were in accordance with the ethical standards of the responsible committee on human experimentation (institutional and national) and with the Helsinki Declaration of 1975, as revised in 2008 .

\section{Statement of Informed Consent}

Informed consent was obtained from all patients for being included in the study.

\section{REFERENCES}

1. Halder RM, Taliaferro SJ. Vitiligo. In: Wolff K, Goldsmith LA, Katz SI, Gilchrest BA, Paller AS, Leffell DJ, editors. Fitzpatrick's dermatology in general medicine. $7^{\text {th }}$ ed. New York: McGraw-Hill Medical; 2008. p. 616-22.

2. Dhar S, Dutta P, Malakar R. Pigmentary disorders. In: Valia RG, Valia AR, editors. IADVL Textbook of Dermatology. $3^{\text {rd }}$ ed. 
Mumbai: Bhalani Publishing House; 2010. p. 749-60.

3. Dutta AK, Dhar S. Vitiligo: past and present. Indian J Dermatol. 2002;47:132-40.

4. Kyriakis KP, Palamaras I, Tsele E, Michailides C, Terzoudi S. Case detection rates of vitiligo by gender and age. Int J Dermatol. 2009;48:328-9.

5. Parsad D, Dogra S, Kanwar AJ. Quality of life in patients with vitiligo. Health Qual Life Outcomes. 2003;1:58.

6. Ohguchi R, Kato H, Furuhashi T, Nakamura M, Nishida E, Watanabe $\mathrm{S}$, et al. Risk factors and treatment responses in patients with vitiligo in Japan-A retrospective large-scale study. Kaohsiung J Med Sci. 2015;31:260-4.

7. Zaima H, Koga M. Clinical course of 44 cases of localized type vitiligo. J Dermatol. 2002;29:15-9.

8. Ongenae K, Van Geel N, Naeyaert J-M. Evidence for an autoimmune pathogenesis of vitiligo. Pigment cell Res. 2003;16:90-100.

9. Lerner A. Vitiligo. J Invest Dermatol. 1959;32:285-310.

10. Huang CL, Nordlund JJ, Boissy R. Vitiligo: a manifestation of apoptosis? Am J Clin Dermatol. 2002;3:301-8.

11. Spritz RA. The genetics of generalized vitiligo: Autoimmune pathways and an inverse relationship with malignant melanoma. Vol. 2, Genome Medicine. 2010. p. 78.

12. Schallreuter KU, Wood JM, Pittelkow MR, Gütlich M, Lemke KR, Rödl W, et al. Regulation of melanin biosynthesis in the human epidermis by tetrahydrobiopterin. Science (80-). 1994;263:1444-6.

13. Kumar R, Parsad D. Melanocytorrhagy and apoptosis in vitiligo: connecting jigsaw pieces. Indian J Dermatol Venereol Leprol. 2012;78:19-23.

14. Hann SK, Chun WH, Park YK. Clinical characteristics of progressive vitiligo. Int J Dermatol. 1997;36:353-5.

15. Nunes DH, Esser LMH. Vitiligo epidemiological profile and the association with thyroid disease. An Bras Dermatol. 2011;86:241-8.

16. Gopal KVT, Rao Gr, Kumar Yh. Increased prevalence of thyroid dysfunction and diabetes mellitus in Indian vitiligo patients: A casecontrol study. Indian Dermatol Online J. 2014;5:456.

17. Gould I, Gray R, Urbaniak S, Elton R, Duncan L. Vitiligo in diabetes mellitus. Br J Dermatol. 1985;113:153-5.

18. Sawicki J, Siddha S, Rosen C. Vitiligo and associated autoimmune disease: retrospective review of 300 patients. J Cutan Med Surg. 2012;16:261-6.

19. Alissa A, Al Eisa A, Huma R, Mulekar S. Vitiligo-epidemiological study of 4134 patients at the National Center for Vitiligo and Psoriasis in Central Saudi Arabia. Saudi Med J. 2011;32:1291-6.

20. Handa S, Kaur I. Vitiligo: clinical findings in 1436 patients. J Dermatol. 1999;26:653-7.

21. Spritzler F. 8 Signs and Symptoms of Vitamin D Deficiency [Internet]. Healthline. 2018 [cited 2018 Dec 8]. Available from: https://www.healthline.com/nutrition/vitamin-d-deficiencysymptoms\#section1

22. West H. 9 Signs and Symptoms of Vitamin B12 Deficiency [Internet]. Healthline. 2017 [cited 2018 Dec 8]. Available from: https://www.healthline.com/nutrition/vitamin-b12-deficiencysymptoms

23. Cafassi J. Folate Deficiency [Internet]. Healthline. 2016 [cited 2018 Dec 8]. Available from: https://www.healthline.com/health/ folate-deficiency

24. Akay BN, Bozkir M, Anadolu Y, Gullu S. Epidemiology of vitiligo, associated autoimmune diseases and audiological abnormalities: Ankara study of 80 patients in Turkey. J Eur Acad Dermatology Venereol. 2010;24:1144-50.

25. Mubki T, Alissa A, Mulekar S, Albargawi S, Youssef M, AlJasser M. Association of vitiligo with anemia, vitamin B12 deficiency, diabetes mellitus, and thyroid dysfunction in Saudi Arab patients: A case control study. J Dermatology Dermatologic Surg. 2017;21:72-6.
26. Kiprono S, Chaula B. Clinical Epidemiological Profile of Vitiligo. East Afr Med J. 2012;89:278-81.

27. Akrem J, Baroudi A, Aichi T, Houch F, Hamdaoui MH. Profile of vitiligo in the south of Tunisia. Int J Dermatol. 2008;47:670-4.

28. Liu J-B, Li M, Yang S, Gui J-P, Wang H-Y, Du W-H, et al. Clinical profiles of vitiligo in China: an analysis of 3742 patients. Clin Exp Dermatol. 2005;30:327-31.

29. Somorin AO, Krahn PM. Vitiligo: A study of 112 cases [2]. Vol. 17, Annals of Saudi Medicine. 1997. p. 125-7.

30. Jarallah JS, Al-Sheikh OA, El-Shabrawy M, Al-Wakeel MA. Vitiligo: Epidemiology and clinical pattern at King Khalid University Hospital. Ann Saudi Med. 1993;13:332-4.

31. Fatani MI, AlSharif SH, Alfif KA, Khan AS, Hussain WA, Banjar AA. The clinical patterns of vitiligo "hospital-based study" in Makkah region, Saudi Arabia. J Dermatology Dermatologic Surg. 2014;18:17-21.

32. AlGhamdi KM. Beliefs and perceptions of Arab vitiligo patients regarding their condition. Int J Dermatol. 2010;49:1141-5.

33. Alzolibani A. Genetic epidemiology and heritability of vitiligo in the Qassim region of Saudi Arabia. Acta Dermatovenerol Alp, Pannonica, Adriat. 2009;18:119-25.

34. Al Robaee AA. Assessment of quality of life in Saudi patients with vitiligo in a medical school in Qassim province, Saudi Arabia. Saudi Med J. 2007;28:1414-7.

35. Shah H, Mehta A, Astik B. Clinical and sociodemographic study of vitiligo. Indian J Dermatol Venereol Leprol. 2008;74:701.

36. Lu T, Gao T, Wang A, Jin Y, Li Q, Li C. Vitiligo prevalence study in Shaanxi Province, China. Int J Dermatol. 2007;46:47-51.

37. Slominski A, Paus R, Bomirski A. Hypothesis: possible role for the melatonin receptor in vitiligo: discussion paper. J R Soc Med. 1989;82:539-41.

38. Ahmad A, Al-Radaddi SM, Al-Ahmadi NN, Bukhari AA, Mahmoud BZ, Aljehani YT. Epidemiology of vitligo and associated autoimmune diseases among patients attending dermatology clinics in Al-Madina 2016-2017. World J Pharm Res. 2017;6:54-74.

39. Vora R V, Patel BB, Chaudhary AH, Mehta MJ, Pilani AP. A Clinical study of vitiligo in a rural set up of Gujarat. Indian J Community Med. 2014;39:143-6.

40. Alissa A, Al Eisa A, Huma R, Mulekar S. Vitiligo-epidemiological study of 4134 patients at the national Center for vitiligo and Psoriasis in Central Saudi Arabia. Saudi Med J. 2011;32:1291-6.

41. Onunu AN, Kubeyinje EP. Vitiligo in the Nigerian African: A study of 351 patients in Benin City, Nigeria. In: Int J Dermatol. 2003. p. $800-2$.

42. AL Fahaad HA. Clinico-epidemiological profile of vitiligo patients in Najran Region, Saudi Arabia. J Dermatology Dermatologic Surg. 2015;19:31-5.

43. Sawicki J, Siddha S, Rosen C. Vitiligo and associated autoimmune disease: retrospective review of 300 patients. J Cutan Med Surg. 2012;16:261-6.

44. Alkhateeb A, Fain PR, Thody A, Bennett DC, Spritz RA. Epidemiology of vitiligo and associated autoimmune diseases in Caucasian probands and their families. Pigment Cell Res. 2003;16:208-14.

45. Zhou H, Wu L-C, Chen M-K, Liao Q-M, Mao R-X, Han J-D. Factors associated with development of vitiligo in patients with halo nevus. Chin Med J (Engl). 2017;130:2703-8.

Copyright by Bilal Ahmad Rahimi, et al. This is an open-access article distributed under the terms of the Creative Commons Attribution License, which permits unrestricted use, distribution, and reproduction in any medium, provided the original author and source are credited.

Source of Support: Nil, Conflict of Interest: None declared. 